\title{
1 A New Route of Synthesis of Na-Mica-4 from
}

\section{Sodalite.}

3 Moisés Naranjo, ${ }^{1}$ Miguel A. Castro, ${ }^{2}$ Agustín Cota, ${ }^{3}$ Esperanza Pavón, ${ }^{2,4}$ M. Carolina

$4 \operatorname{Pazos}^{5}$ and María D. Alba ${ }^{2, *}$

$5 \quad{ }^{1}$ Consejería de Educación. Junta de Andalucía. 41092 Sevilla. Spain

$6 \quad{ }^{2}$ Instituto de Ciencia de Materiales de Sevilla. Consejo Superior de Investigaciones

7 Científicas -Universidad de Sevilla. Avda Américo Vespucio 49. 41092 Sevilla. Spain.

$8 \quad{ }^{3}$ Laboratorio de rayos-X (CITIUS), Avda. Reina Mercedes 4b, 41012-Sevilla. Spain.

$9 \quad{ }^{4}$ Unité de Catalyse et de Chimie du Solide, UCCS, CNRS, UMR8181, Université Lille

10 Nord de France, 59655 Villeneuve d'Ascq. France.

$11{ }^{5}$ Escuela de Ciencias Químicas, Universidad Pedagógica y Tecnológica de Colombia

12 UPTC, Avda. Central del Norte, Vía Paipa, Tunja, Boyacá, Colombia

14 ABSTRACT: Synthesis of Na-Mica-4 has been achieved by a "mix and calcine" 15 method using sodalite and magnesium fluoride as the only precursors. Previous research 16 found sodalite as a key intermediate reaction product in the formation of Na-Mica-4 17 when the $\mathrm{NaCl}$ melt method was employed. Similarities in structure, chemical 18 composition and cation distribution in products using the proposed method and the

$19 \mathrm{NaCl}$ melt method are described and suggest that Na-Mica-4 is a very stable product.

20 The use of sodalite as precursor provokes microporous formation in the final mica. The

21 absence of excess $\mathrm{Na}$ leads to a lower particle size and to the presence of less impurity

\footnotetext{
* Corresponding Author: Tel: +34 954489546. Fax: + 34 954460665. E-mail: alba@icmse.csic.es
} 
1 in the calcined product. Different sodalites could be used in the synthesis of different

2 Na-Mica-4 with presumably different physicochemical properties.

3

4 Keywords. Brittle micas, sodalite, rheology, swelling 2:1 phyllosilicates, surface, 5 particle size, XRD, MAS NMR.

6

\section{Graphical abstract}

8

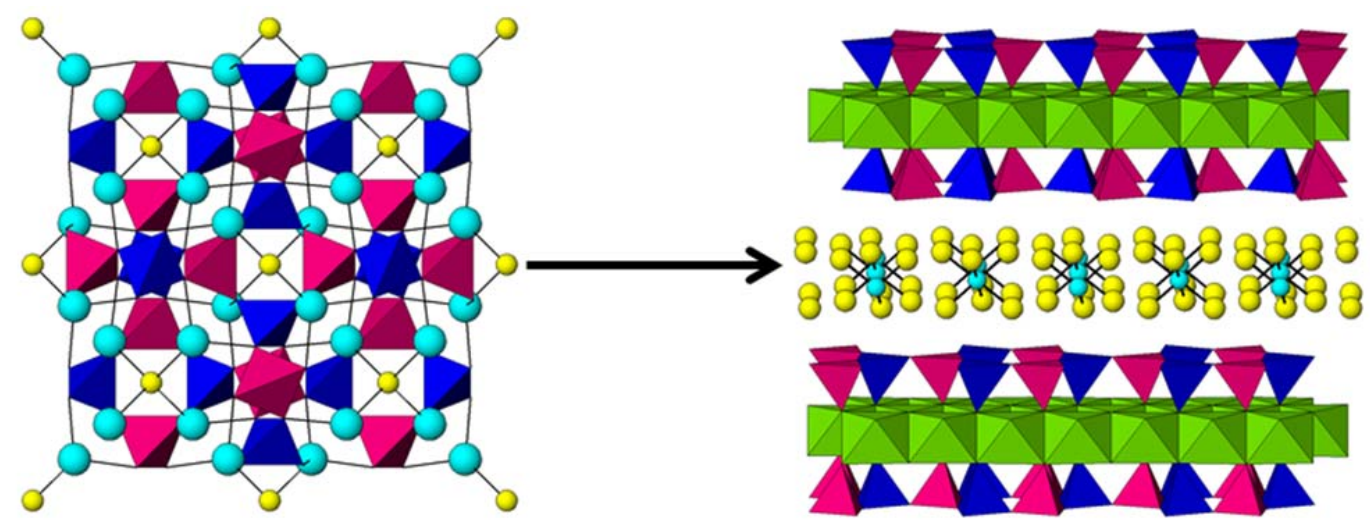




\section{1. Introduction}

Na-Mica-4 is a synthetic high-charge expandable phyllosilicate with no other natural equivalent, as it expands in contact with water while its charge is in the range of that of brittle micas $[1,2]$. Because of this, much research on its synthesis and cationexchange properties has been developed over the last few years. Na-Mica-4 was first synthesized by Gregorkiewitz and Rausell-Colom [3] in minor quantities as one out of several products from melting augite powder in fluoride salts. Electron microprobe analysis and Infrared spectra suggested the presence of four $\mathrm{Na}^{+}$cations per unit cell. In addition, it was observed that the product expanded in the presence of water vapor. Particle sizes were non uniform, ranging from $0.2 \mu \mathrm{m}$ to $2 \mathrm{~mm}$. The unique characteristics of this synthetic silicate fostered interest in attaining bulk synthesis of the product with particle sizes less than $2 \mu \mathrm{m}$, in order to make it amenable to cation exchange. For its synthesis, different routes and precursors were tested. These methods sought: i) products free from impurities, and, ii) cheaper silicon sources. Paulus et al. [4] made a big step forward using a sol-gel route with $\mathrm{Mg}\left(\mathrm{NO}_{3}\right), \mathrm{Al}\left(\mathrm{NO}_{3}\right)_{3}$ and TEOS, subsequent mixture with $\mathrm{NaF}$ and calcination, obtaining a product with particle sizes in the range $1 \mu \mathrm{m}-5 \mu \mathrm{m}$, showing selectivity towards retention of radionuclides such as ${ }^{90} \mathrm{Sr}$. However, the synthesis process was rather long and tedious, and repeated washings in boric acid and water were necessary to remove different impurities $[5,6]$. Franklin and Lee [7] developed the so-called "all in one" method, in which all the steps in the sol-gel method were merged together, with no or little effect in purity and particle size. Regarding the second objective, several studies were conducted with the aim of finding more cost-effective aluminosilicate sources, such as fly ashes [8] or kaolinite [1], for future large-scale applications, finding metakaolinite as an optimal precursor with the desired 1:1 Si to Al molar ratio but with the inconvenience of aluminum being in a 
1 different coordination number [9]. In this case, $\mathrm{Al}$ was not in tetrahedral coordinated in

2 the precursor, which can be an important factor for cation distribution in the synthesized

3 product. In addition, the need for removing impurities with boric acid washings

4 remained. To avoid these problems, Park et al. [10] developed a new route, the so-called

5 "NaCl melt method", in which $\mathrm{NaCl}$ and $\mathrm{MgF}_{2}$ were employed instead of $\mathrm{NaF}$ as

6 sodium and fluorine sources, obtaining a nearly pure Na-Mica-4, making boric acid

7 washings unnecessary. Particle size was shown to be dependent on the amount of $\mathrm{NaCl}$

8 in the reactant mixture, finding the ratio $\mathrm{NaCl} / \mathrm{Al}_{2} \mathrm{O}_{3}=4$ to be optimal for obtaining

9 average particle sizes around $3 \mu \mathrm{m}$. To achieve ultrafine $(<2 \mu \mathrm{m})$ products, ratios as high

10 as 6 were required. Thus, smaller particle size required high $\mathrm{NaCl}$ excess, with

11 damaging effects in purity and crystallinity. This fact shows that it would be interesting

12 to look for a synthesis method in which no $\mathrm{NaCl}$ excess were necessary.

13 Another important aspect to be considered is the framework cation ordering, as

14 Si-Al distribution strongly affects reactivity of layer silicates [11]. Gregorkiewitz and

15 Rausell-Colom [3] interpreted the lower frequency shifts in the infrared spectrum as

16 indicative of high $\mathrm{Al}$ for Si substitution, noting that a different layer stacking mode,

17 necessary to accommodate the high number of interlayer cations in the silicate, could

18 affect Si-Al distribution in a different way to that previously expected [12]. Therefore, it

19 is quite important for the synthesis of Na-Mica-4 with design properties to relate the

20 synthesis procedure with the $\mathrm{Si}-\mathrm{Al}$ distribution of the as-made product. The appropriate

21 technique is the ${ }^{29} \mathrm{Si}$ MAS NMR which is sensible to the local ordering and, therefore,

22 to the Si-Al distribution in the tetrahedral sheet [13]. However, not many NMR studies

23 have been performed on the Na-Mica-4. Komarneni et al. [9] attributed two peaks

24 separated by $1.9 \mathrm{ppm}$ to one single $\mathrm{Si}$ environment, considering this observation an

25 indication of homogeneous $\mathrm{Si}$-Al distribution and, presumably, of better cation 
1 exchange and selectivity properties. As a result of quantitative ${ }^{27} \mathrm{Al}$ NMR study, a $97 \%$

2 of aluminum was estimated to be in tetrahedral coordination. Park et al. [10] found two

3 peaks at -78.2 and $-81.7 \mathrm{ppm}$ which were assigned to $\mathrm{Q}^{3}(3 \mathrm{Al})$ and $\mathrm{Q}^{3}(2 \mathrm{Al}) \mathrm{Si}$

4 contributions. Komarneni et al. [14] found four ${ }^{29} \mathrm{Si}$ peaks (although spectra were not

5 showed) and an additional peak when heating over $1000^{\circ} \mathrm{C}$. Alba et al. [15] identified

6 five different ${ }^{29}$ Si peaks, attributing the "fifth peak" to a violation of Loewestein's rule.

7 The use of precursors having $\mathrm{Si}$ and $\mathrm{Al}$ in the same ratio and coordination as in the

8 target product is then believed to be helpful to attain a homogeneous Si-Al distribution

9 and no or little $\mathrm{Al}$ in the octahedral layer.

10 Other characterization techniques, such as Z-potential and BET surface, which

11 could be helpful to understand key properties like cation exchange kinetics and colloids

12 properties, have not been considered so far.

13 Therefore, the goal of this research was to provide a new synthesis route for Na-

14 Mica-4 using sodalite as aluminum and silicon source. The use of sodalite was based on

15 the fact that this silicate has a $\mathrm{Si} / \mathrm{Al}$ ratio equal to 1 and both heteroatoms are

16 homogeneous distributed. Moreover, the Al coordination sphere in the starting material

17 is similar to this found in the final product. Finally, the purity, Si-Al distribution,

18 particle size, Z-potential and surface are analyzed and the influence on these properties

19 of the synthesis precursors will be discussed.

\section{2. Experimental}

\subsection{Synthesis method.}

A single-step procedure described elsewhere [15], similar to the $\mathrm{NaCl}$ melt method [10], was employed in the synthesis of Na-Mica-4. Starting materials were $\mathrm{SiO}_{2}$ 
1 no. $21645-51-2,99 \%$ purity), $\mathrm{MgF}_{2}$ from Aldrich (CAS no. 20831-0, 98\% purity), and

$2 \mathrm{NaCl}$ from Panreac (CAS no. 131659, 99.5\% purity). The reactants were mixed in the

3 following molar ratio: $4 \mathrm{SiO}_{2}: 4 \mathrm{Al}(\mathrm{OH})_{3}: 6 \mathrm{MgF}_{2}: 8 \mathrm{NaCl}$. The mixture was ground in an

4 agate mortar and heated in a Pt crucible at $900^{\circ} \mathrm{C}$ for $15 \mathrm{~h}$. After cooling, the solids

5 were washed in deionized water and dried at room temperature. This sample will be

6 named as $\mathrm{Na}-\mathrm{Mica}-4$.

7 Other set of samples were synthesized using sodalite, synthetized following the

8 method described by Acar et al. [16], as $\mathrm{Na}, \mathrm{Al}$ and $\mathrm{Si}$ source. Sodalite, $\mathrm{MgF}_{2}$ and $\mathrm{NaCl}$

9 were mixed in different molar stoichiometric amount: 2/3:6:4 for sample Na-Mica-4-S1

10 and 2/3:6:0 for sample Na-Mica-4-S2. Both mixtures were ground in an agate mortar

11 and heated in Pt crucibles at $900^{\circ} \mathrm{C}$ for $15 \mathrm{~h}$. After cooling, the solids were washed in

12 deionized water and dried at room temperature.

$14 \quad$ 2.2. Sample characterization.

TG/DTA experiments were carried out using a TA (model STD-Q600)

16 instrument, with alumina as reference. The samples were placed into Pt crucibles and

17 maintained at air throughout the heating period. The temperature was increased at a

18 constant rate of $10^{\circ} \mathrm{C} / \mathrm{min}$.

19 The external specific area $\left(\mathrm{S}_{\mathrm{BET}}\right)$ and microporous surface area $\left(\mathrm{S}_{\mu}\right)$ were

20 determined by nitrogen adsorption at $77 \mathrm{~K}$ using a Micromeritics model ASAP 2010

21 and all samples were dried at $100{ }^{\circ} \mathrm{C}$ overnight under vacuum before the nitrogen

22 sorption measurement [17]. The BET surface area has been calculated using the

23 complete $\mathrm{N}_{2}$ adsorption isotherm and applying the following formulae [18]:

$$
S_{B E T}=\frac{V_{m} \cdot N \cdot s}{V \cdot a}
$$


1 where $V_{m}$ is in units of volume which are also the units of the molar volume of the

2 adsorbate gas, $N$ is Avogadro's number, $s$ the adsorption cross section of the adsorbed

3 species, $V$ the molar volume of the adsorbate gas, an $a$ the mass of the adsorbent. The

4 correlation coefficient was 0.9996 .

The particle size distribution of water suspension was measured using a laser

6 diffraction particle size analyzer (Mastersize 2000 Model Hydro2000SM, Malvern

7 Instrument Ltd., UK). The size-frequency distributions were plotted and $\mathrm{D}_{10 \%}, \mathrm{D}_{50 \%}$ and

$8 \mathrm{D}_{90 \%}$, volume number diameters where the indicated percentage of the particles is

9 smaller than that size, were determined. In addition, the size distribution was computed

10 in terms of the polydispersity index (PI) and expressed as [19]:

$$
P I=\frac{D_{90 \%}-D_{10 \%}}{D_{50 \%}}
$$

The zeta potential of all the samples was measured by using a laser Doppler

12 electrophoresis analyzer (Zetasizer Nano ZS, Malvern Instrument Ltd., UK). The 13 temperature of the samples was controlled at $25{ }^{\circ} \mathrm{C}$. The dispersions were diluted to 0.1

$14 \mathrm{mg} / \mathrm{mL}$ with the help of an ultrasonic for 10 minutes prior to the measurements. XRD patterns were obtained with a Bruker D8 instrument using $\mathrm{Cu} \mathrm{K}_{\alpha}$ radiation at $40 \mathrm{kV}$ and $40 \mathrm{~mA}$. Diffractograms were obtained from 3 to $70^{\circ} 2 \theta$ at a scanning speed of $1^{\circ} 2 \theta \mathrm{min}^{-1}$ with a scan step of $0.05^{\circ} 2 \theta$.

The morphology of the samples was analyzed by SEM (JEOL, Model JSM 5400 ) at $20 \mathrm{kV}$. An EDX system (Oxford Link ISIS) was fitted to the SEM equipment to 20 perform chemical analyses of the samples using a $\mathrm{Si} / \mathrm{Li}$ detector with Be window. Single-pulse (SP) MAS NMR experiments were recorded on a Bruker DRX400 spectrometer equipped with a multinuclear probe. Powdered samples were packed in 4

$23 \mathrm{~mm}$ zirconia rotors and spun at $10 \mathrm{kHz}$. The ${ }^{1} \mathrm{H}$ MAS spectra were obtained using 24 typical $\pi / 2$ pulse widths of $4.1 \mu \mathrm{s}$ and a pulse space of $5 \mathrm{~s} .{ }^{29} \mathrm{Si}$ MAS NMR spectra were 
1 acquired at a frequency of $79.49 \mathrm{MHz}$, using a pulse width of $2.7 \mu \mathrm{s}(\pi / 2$ pulse length $=$

$27.1 \mu \mathrm{s}$ ) and delay times in the range $3 \mathrm{~s}-60 \mathrm{~s} .{ }^{27} \mathrm{Al}$ MAS NMR spectra were recorded at $3 \quad 104.26 \mathrm{MHz}$ with a pulse width of $0.92 \mu \mathrm{s}(\pi / 2$ pulse length $=9.25 \mu \mathrm{s})$ and a delay time 4 of $0.5 \mathrm{~s}$. The chemical shift values were reported in ppm from tetramethylsilane for ${ }^{29} \mathrm{Si}$ 5 and ${ }^{1} \mathrm{H}$ and from a $0.1 \mathrm{M} \mathrm{AlCl}_{3}$ solution for ${ }^{27} \mathrm{Al}$.

6

\section{$7 \quad$ 3. Results and Discussion}

X-ray diffractograms of the samples (Figure 1) show that bulk synthesis of

9 hydrated 2:1 phyllosilicate has been attained in all cases and minor reflections from 10 neighbourite $\left(\mathrm{MgNaF}_{3}\right)$ is observed. Complete suppression of amorphous mica 11 formation has been achieved as reported by others who used kaolinite [1] or fumed 12 silica [8].

Additionally, sodalite reflections are still present in Na-Mica-4-S1; the XRD 14 pattern of the precursor, sodalite, has been included in the Figure 1d. When sodalite is employed as precursor in the synthesis of Na-Mica-4, excess $\mathrm{Na}$ is no longer needed as proposed by Park et al. [10]. Moreover, the excess of $\mathrm{NaCl}$ promoted the presence of the precursor. Therefore, the use of an excess of $\mathrm{NaCl}$ would be necessary for the synthesis of the reaction intermediate sodalite, rather than for the synthesis of the Na-Mica-4 [10]. The XRD patterns of all the samples show a unique 001 reflection corresponding to a basal space of $12.1 \AA$ due to hydrated $\mathrm{Na}^{+}[20]$. Thus, the use of sodalite as starting material did not provoke the formation of anhydrous phases as previously observed when fly ash was used [8]. The effect of the synthesis method on the hydration state of the micas has been analyzed by thermal analysis and by ${ }^{1} \mathrm{H}$ MAS NMR. endothermic response, at $75.7^{\circ}-77.8^{\circ} \mathrm{C}$, accompanied by a weight loss at temperatures 
1 below $150^{\circ} \mathrm{C}$, due to the dehydration of the external surface and of the interlayer space

2 of the micas [10]. A similar weight loss has been observed in all the samples, estimated

3 to be 6.41-6.68 \% of total weight (Table 1) and it corresponds with a value of ca. 0.78

4 water molecules per interlayer cation, similar to the data reported by Park et al. [10] The

5 hydration state of the interlayer cation was corroborated by ${ }^{1} \mathrm{H}$ MAS NMR (Figure 2)

6 that showed a wide signal at $4.6 \mathrm{ppm}$ due to the $\mathrm{Na}^{+}$hydration water (21). The ${ }^{1} \mathrm{H}$ MAS

7 NMR spectra of the Na-Mica-4 synthesized with $\mathrm{NaCl}$ excess (Figure $2 \mathrm{a}$ and $2 \mathrm{~b}$ ) show

8 an additional signal at $1.1 \mathrm{ppm}$ due to terminal $\mathrm{SiOH}$ groups at the crystal surface and at

9 crystal defect [13]. Finally, the spectrum of Na-Mica-4-S1 (Figure 2b) showed a signal

10 at $3.7 \mathrm{ppm}$ due to bridging $\mathrm{Si}(\mathrm{OH}) \mathrm{Al}$ hydroxyl groups typical of zeolite framework as

11 can be seen in the spectrum of sodalite (Figure 2d) [13].

12 All the micas exhibited similar long range order and swelling capacity but their

13 particles showed different morphology as being observed by SEM (Figure 3). Whereas

14 Na-Mica-4 (Figure 3a) shows tiny flakes particles, the micas synthesized from sodalite

15 show particles with a hexagonal morphology with well-defined angles of ca. $120^{\circ}$

16 similar to the phlogopite crystal described by Sunagawa and Tomura [22] and the Na-

17 Mica-4 synthesized by Gregorkiewitz and Rausell-Colom [3]. Na-Mica-4-S2 particles

18 (Figure 3c) are smaller than Na-Mica-4-S1 one (Figure 3b). It is well known that small

19 particle size favors the kinetic of cation uptake [9] and consequently their potential use

20 as decontaminants. Park et al. [10] observed that, when excess of $\mathrm{NaCl}$ was used during

21 the synthesis, larger amounts of $\mathrm{NaCl}$ led to smaller crystal size; however, the synthesis

22 from sodalite leads smaller particles size at $\mathrm{Al} / \mathrm{Na}$ ratio equal 1.

For its decontamination application, properties such as surface area, particle size

24 distribution and Z-potential are important (Table 2) because they will be directly related

25 to its adsorption capacity and reactivity. The particle diameter of the micas occurs as 
1 distinct domains showing a bimodal character of this distribution (Figure S1). The main

2 mode of Na-Mica-4 is close to $4 \mu \mathrm{m}$ and the second is at $42 \mu \mathrm{m}$. The relative intensity

3 of the second mode increases when sodalite is used as starting material and it is even

4 higher in presence of $\mathrm{NaCl}$ excess. $D_{50 \%}$ and PI of all dispersions are shown in Table 2.

5 The synthesis from sodalite gives micas with statistically higher size and a narrower

6 size of distribution. However, the different particles sizes do not significantly affect the

7 total surface area but influence the microporosity which increases with the use of

8 sodalite as starting material and $\mathrm{NaCl}$ in stoichiometric quantity.

The surface charge property can be characterized by zeta potential and the

10 stability of a clay solution can be measured depending of its value. Colloids with high

11 Z-potential (negative or positive) are electrically stabilized while colloids with low Z-

12 potential tend to coagulation or flocculated. Z-potential values of micas have not shown

13 relation with the particle size of colloid suspension but are related to the precursor

14 nature (Table 2). For all the micas, the Z-potential is negative as can be expected for

15 clay minerals; however, its value is strongly dependent of the chemical composition and

16 the stoichiometry of the synthesis mixture. The excess of $\mathrm{NaCl}$, when sodalite was used

17 as starting material, tends to cause aggregation, as seen by the higher $\mathrm{D}_{50 \%}$ value,

18 resulting from the interaction between the positive sodium ion and the negative edges of

19 the clay particle. Similar observation was made in montmorillonite which had slightly

20 higher (less negative) values for Z-potential in the presence of $\mathrm{Li}^{+} \mathrm{Or} \mathrm{Na}^{+}[23,24]$. The

21 Na-Mica-4 colloid, despite of the $\mathrm{NaCl}$ excess, is electrically stabilized; the Z-potential

22 values were higher than \pm 10 which indicate that they don't tend to coagulate or 23 flocculate [25].

24 Finally, the framework cation distribution has been analyzed by ${ }^{29} \mathrm{Si}$ and ${ }^{27} \mathrm{Al}$

25 MAS NMR (Figure 4 and 5). The ${ }^{29}$ Si MAS NMR spectrum of the precursor, sodalite, 
1 (Figure $4 \mathrm{~d}$ ) shows a unique signal at $-85 \mathrm{ppm}$ due to $\mathrm{Q}^{4}(4 \mathrm{Al})$ Si environment (26);

2 however, the ${ }^{29} \mathrm{Si}$ MAS NMR spectra of all the micas (Figure 4a-c) are characterized by

3 a set of signal between -70 and -90 ppm, compatible with the existence of several single

$4 \mathrm{Q}^{3}(\mathrm{nAl})$ environments as expected for 2:1 layered aluminosilicates [27]. The four

5 distinct Si signals at lower frequencies are assigned to $\mathrm{Q}^{3}(\mathrm{nAl}) \mathrm{Si}$ environments and the

6 fifth signal at $-75 \mathrm{ppm}$ to $\mathrm{Q}^{3}(3 \mathrm{Al})$ with Al-O-Al linkages [15]. ${ }^{29} \mathrm{Si}$ spectra of the three

7 products are basically identical in shape and peak positions, the differences found only

8 in slight changes in relative areas of peaks (Figure 4, right). It is noticeable that the Si-

9 Al distribution is not significantly affected by the precursor but is influenced by the

10 excess of $\mathrm{NaCl}$ which favours the peak at ca. $-75 \mathrm{ppm}$ and diminishes the intensity of

11 the peaks of the $\mathrm{Q}^{3}(\mathrm{nAl})(\mathrm{n} \leq 1)$ Si environment.

${ }^{27} \mathrm{Al}$ MAS NMR spectra (Figure 5) show a main peak at ca. 65 ppm due to the majority of $\mathrm{Al}$ is in tetrahedral coordination [13], micas having higher quadrupole interactions than sodalite as inferred by the lower frequencies asymmetry of the peak. A sodalite contribution is clearly present in Na-Mica-S1 (Figure 5b), in accordance with the presence of this phase in the XRD data. Additionally, in all the micas, a small peak at ca. 0 ppm is observed and has been interpreted as aluminium in the octahedral layer [15]. The relative intensity of this peak diminishes when sodalite is used as precursor as it can be expected when aluminium in the source exhibits similar coordination than the 20 final product.

\section{Conclusions}

Synthesis of Na-Mica-4 from sodalite, an intermediate product in the synthesis

24 of that mica when the NaCl-melt method is employed, has been carried out successfully with and without excess of $\mathrm{NaCl}$. This result can be useful when considering tailor- 
1 made synthesis methods in which very specific compositions and/or physicochemical

2 properties of the layer silicate are required. When sodalite is used as starting material,

3 the $\mathrm{NaCl}$ excess inhibits the total conversion of sodalite to mica. Therefore, the use of

4 an excess of $\mathrm{NaCl}$ is only necessary for the synthesis of the reaction intermediate

5 sodalite, rather than for the synthesis of the Na-Mica-4.

6 The chemical composition of the starting mixture does not affect the mica 7 crystallinity although the morphology and the particle size depend on the silicon and 8 aluminum source and the $\mathrm{Al} / \mathrm{Na}$ ratio. Both factors are also responsible of its colloidal 9 behavior.

10 Finally, the use of sodalite as starting material provokes the microporous 11 formation in the final mica which is enhanced in absence of $\mathrm{NaCl}$ excess.

\section{Acknowledgments}

We gratefully acknowledge financial support from FEDER funds and DGICYT

Projects no. CTQ2010-14874. We thanks to the Instituto Ciencia de los Materiales de

Sevilla (CSIC-University of Seville) for the instrumental facility for measuring

17 SEM/EDX, $\mathrm{N}_{2}$ isotherm and MAS-NMR and to the CITIUS, University of Seville, for 18 the instrumental facility for measuring XRD, Z-potential and particle size distribution.

\section{References}

[1] T. Kodama, S. Komarneni, J. Mater. Chem., 9 (1999) 2475-2480.

[2] S. Komarneni, W.J. Paulus, R. Roy, Proc. Int. Conf. Ion Exchange: Tokyo, 1991.

[3] M. Gregorkiewitz, J.A. Rausell-Colom, Amer. Miner. 72 (1987) 515-527.

[4] W.J. Paulus, S. Komarneni, R. Roy, Letters to Nature 357 (1992) 571-573 
[5] T. Kodama, T. Higuchi, T. Shimizu, K. Shimizu, S. Komarneni, W. Hofbauer, H. Schneider, J. Mater. Chem. 11 (2001) 2072-2077.

[6] T. Kodama, K. Hasegawa, K. Shimizu, S. Komarneni, Sep. Sci. Technol. 38 (2003) 679-694.

[7] K.R. Franklin, E. Lee, J. Mat. Chem. 6 (1996) 109-115.

[8] M. Park, D.H. Lee, C.L. Choi, W.T. Lim, S.K. Lee, N.H. Heo, S. Komarneni, J. Choi J. Porous. Mater. 9 (2002) 291-298.

[9] P. Komarneni, R. Pidugi, J.E. Amonette J. Mater. Chem 8 (1998) 205-208.

[10] M. Park, D. H. Lee, C. L. Choi, S.S. Kim, K.S. Kim, J. Chem. Mater. 14 (2002) $2582-2589$.

[11] M.D. Alba, A.I. Becerro, M.A. Castro, A.C. Perdigon, Am. Miner. 86 (2001) 124-131.

[12] E.W. Radolovich, Amer. Miner. 48 (1963) 76-99.

[13] G. Engelhardt, D. Michel, High-Resolution Solid-State NMR of Silicates and Zeolites. John Wiley \& Sons: New York, 1987.

[14] S. Komarneni, R. Ravella, M. Park, J. Mater. Chem. 15 (2005) 4241-4245.

[15] M.D.Alba, M.A.Castro, M. Naranjo, E. Pavón, Chem. Mater. 18 (2006) 28672869.

[16] A. Acar, H.Yücel, A. Culfaz, Chem. Eng. Comm. 190 (2003) 861-882.

[17] K.S.W. Sing, Pure \& Appl. Chem. 54 (1982) 2201-2218.

[18] S. Brunauer, P. H. Emmett and E. Teller, J. Am. Chem. Soc., 60 (1938) 309-319

[19] J.J. Torrado, L. Illum, S.S. Davis, Int. J. Pharm. 51 (1989) 85-93.

[20] M.D. Alba, A.I. Becerro, M.A. Castro, A.C. Perdigon, Am. Miner. 86 (2001) 115123. 
[21] M.D. Alba, M.A. Castro, A.I. Becerro, A.C. Perdigón, J.Phys. Chem. 107 (2003) $3996-4001$.

[22] I. Sunagawa, S. Tomura, Amer. Miner. 61 (1976) 939-943.

[23] A. Kaya, Y. Yukselen, Can. Geotech. J. 42 (2005) 1280-1289.

[24] F. Rao, F.J. Ramirez-Acosta, R.J. Sanchez-Leija, S. Song, A. Lopez-Valdivieso, Appl. Clay Sci. 51 (2011) 38-42.

[25] R. Greenwood, K. Kendall, J. Eur. Ceram. Soc. 19 (1999) 479-488.

[26] B.L. Sherriff, H.D. Grundy, J.S. Hartman, European J. Mineralogy 3 (1991) 751 768.

[27] J. Sanz, J.M. Serratosa, J. Am. Chem. Soc. 106 (1984) 4790-4793. 
Table 1.

DTA and TG data.

\begin{tabular}{cccc}
\hline & DTA & \multicolumn{2}{c}{${\mathrm{TG}\left(25^{\circ}-300^{\circ} \mathrm{C}\right)}$} \\
\cline { 2 - 4 } & $\mathrm{T}\left({ }^{\circ} \mathrm{C}\right)$ & $\%$ & molec $\mathrm{H}_{2} \mathrm{O} /$ cation \\
\hline Na-Mica-4 & 76.0 & 6.68 & 0.79 \\
Na-Mica-4-S1 & 75.7 & 6.41 & 0.76 \\
Na-Mica-4-S2 & 77.8 & 6.62 & 0.78 \\
\hline
\end{tabular}

Table 2.

Cumulated particle size at 50\% distribution, polydispersity index, surface areas (BET and microporous) and zeta potential.

\begin{tabular}{cccccc}
\hline & $\begin{array}{c}\mathrm{D}_{50 \%} \\
(\mu \mathrm{m})\end{array}$ & $\mathrm{PI}$ & $\begin{array}{c}\mathrm{S}_{\mathrm{BET}} \\
\left(\mathrm{m}^{2} / \mathrm{g}\right)\end{array}$ & $\begin{array}{c}\mathrm{S}_{\mu} \\
\left(\mathrm{m}^{2} / \mathrm{g}\right)\end{array}$ & $\begin{array}{c}\text { Z-potential } \\
(\mathrm{mV})\end{array}$ \\
\hline Na-Mica-4 & 16.1 & 5.4 & 6.2 & 0.6 & -50.9 \\
Na-Mica-4-S1 & 35.0 & 4.3 & 5.7 & 1.6 & -14.1 \\
Na-Mica-4-S2 & 24.8 & 4.7 & 5.2 & 2.7 & -31.6 \\
\hline
\end{tabular}




\section{FIGURE CAPTION}

Fig. 1. XRD of a) Na-Mica-4, b) Na-Mica-4-S1, c) Na-Mica-4-S2, and, d) sodalite. $s=$ sodalite (PDF 00-002-0052), and, $\mathrm{f}=\mathrm{MgNaF}_{3}(\mathrm{PDF}$ 04-015-3231).

Fig. 2. ${ }^{1} \mathrm{H}$ MAS NMR spectra of a) Na-Mica-4, b) Na-Mica-4-S1, c) Na-Mica-4-S2, and, d) sodalite.

Fig. 3. SEM micrography of a) Na-Mica-4, b) Na-Mica-4-S1, and, c) Na-Mica-4-S2.

Fig. 4. ${ }^{29}$ Si MAS NMR spectra (left) of a) Na-Mica-4, b) Na-Mica-4-S1, c) Na-Mica-4S2, and, d) sodalite and the percentage of the $\mathrm{Q}^{3}(\mathrm{nAl})$ Si environments (right).

Fig. 5. ${ }^{27}$ Al MAS NMR spectra of a) Na-Mica-4, b) Na-Mica-4-S1, c) Na-Mica-4-S2, and, d) sodalite. 
Figure 1

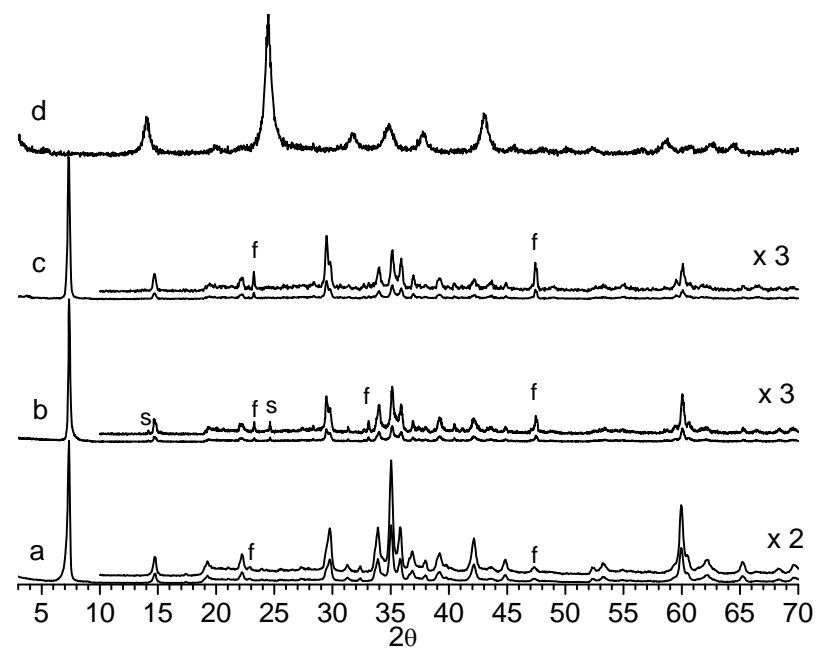


Figure 2

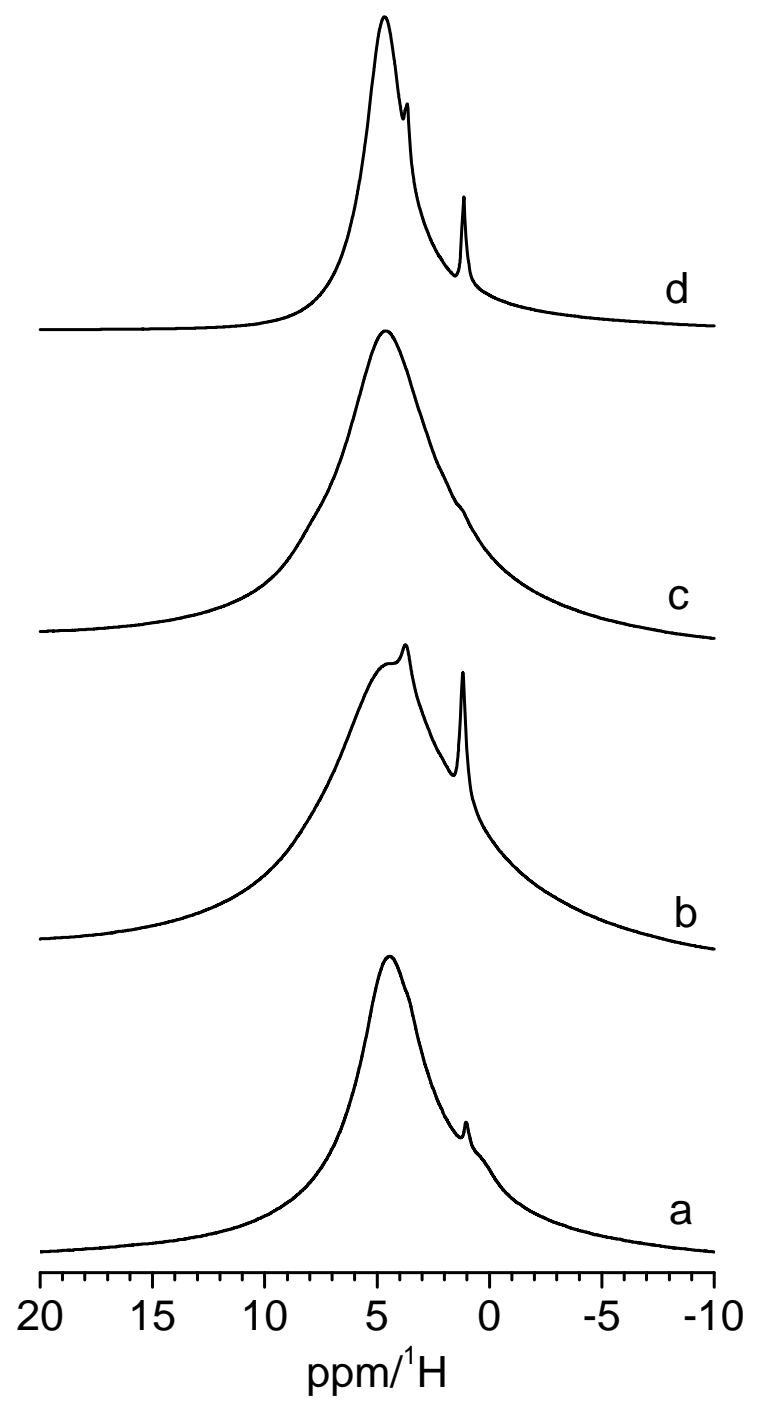


Figure 3

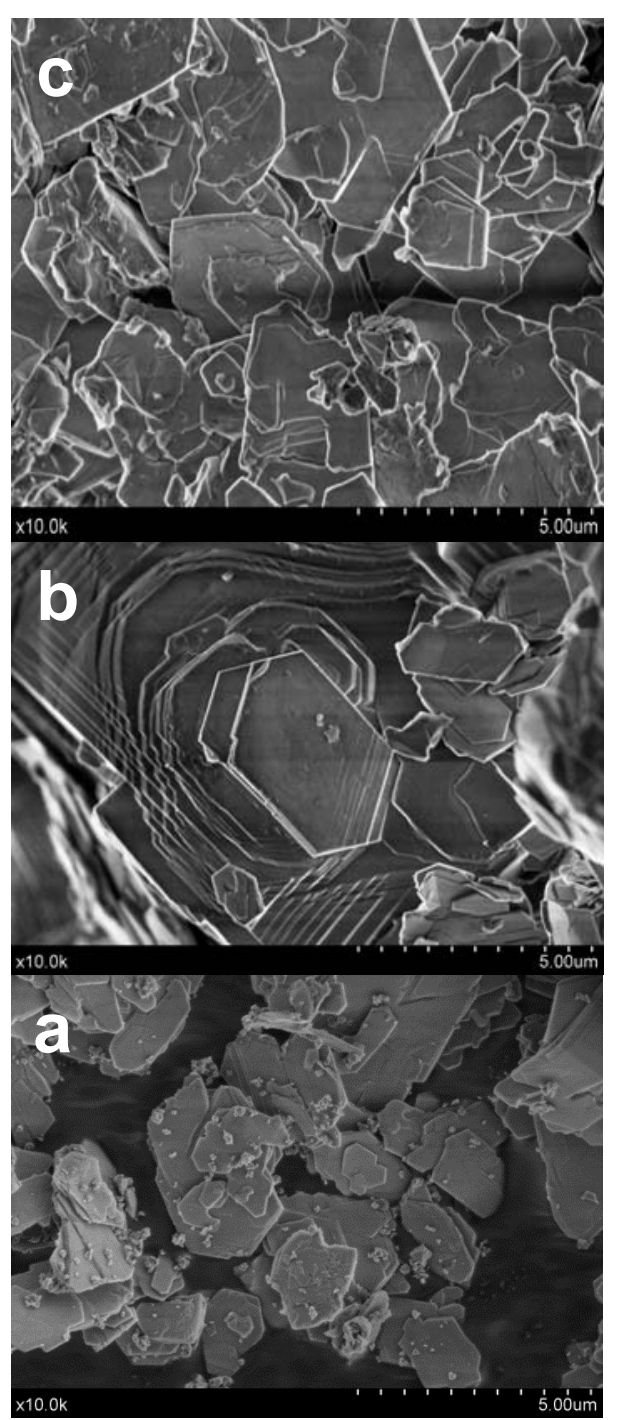


Figure 4

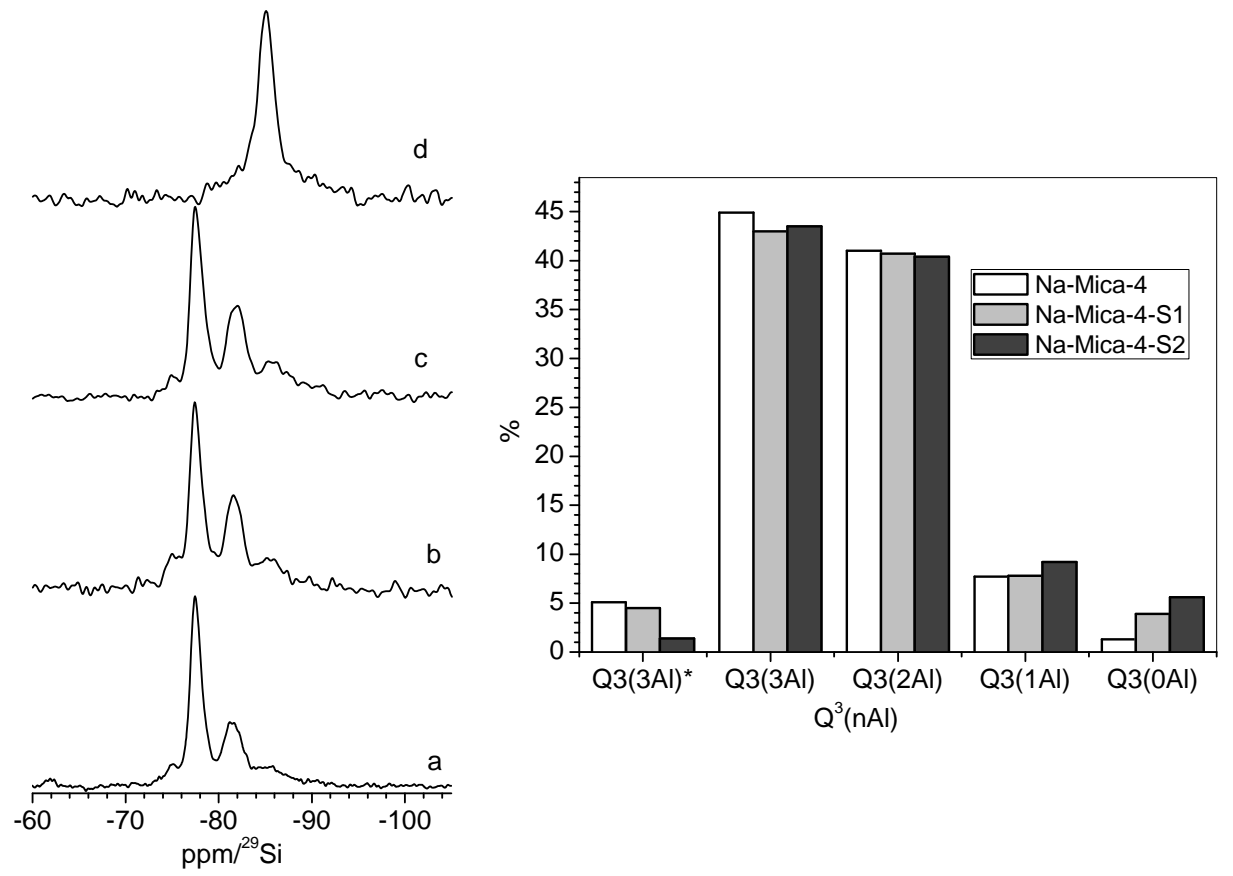


Figure 5

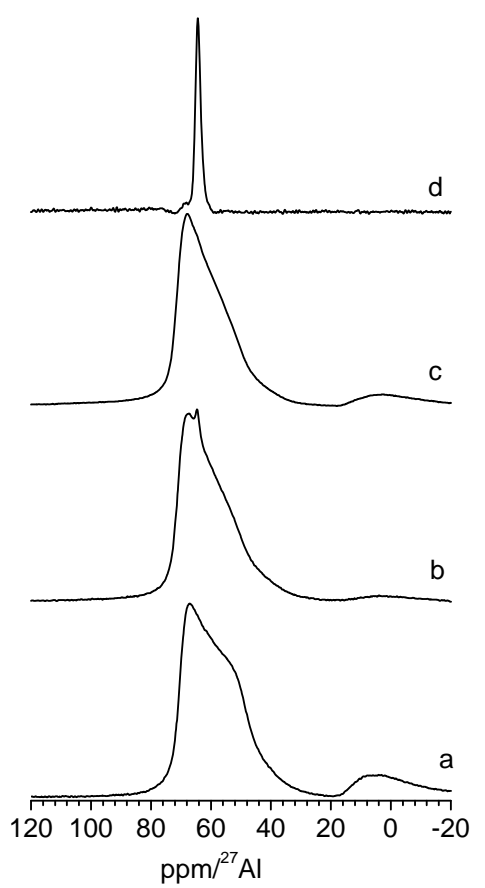




\section{SUPPORTING INFORMATION}

Fig. S1. Particle Size distribution of a) Na-Mica-4, b) Na-Mica-4-S1, and, c) Na-Mica4-S2.
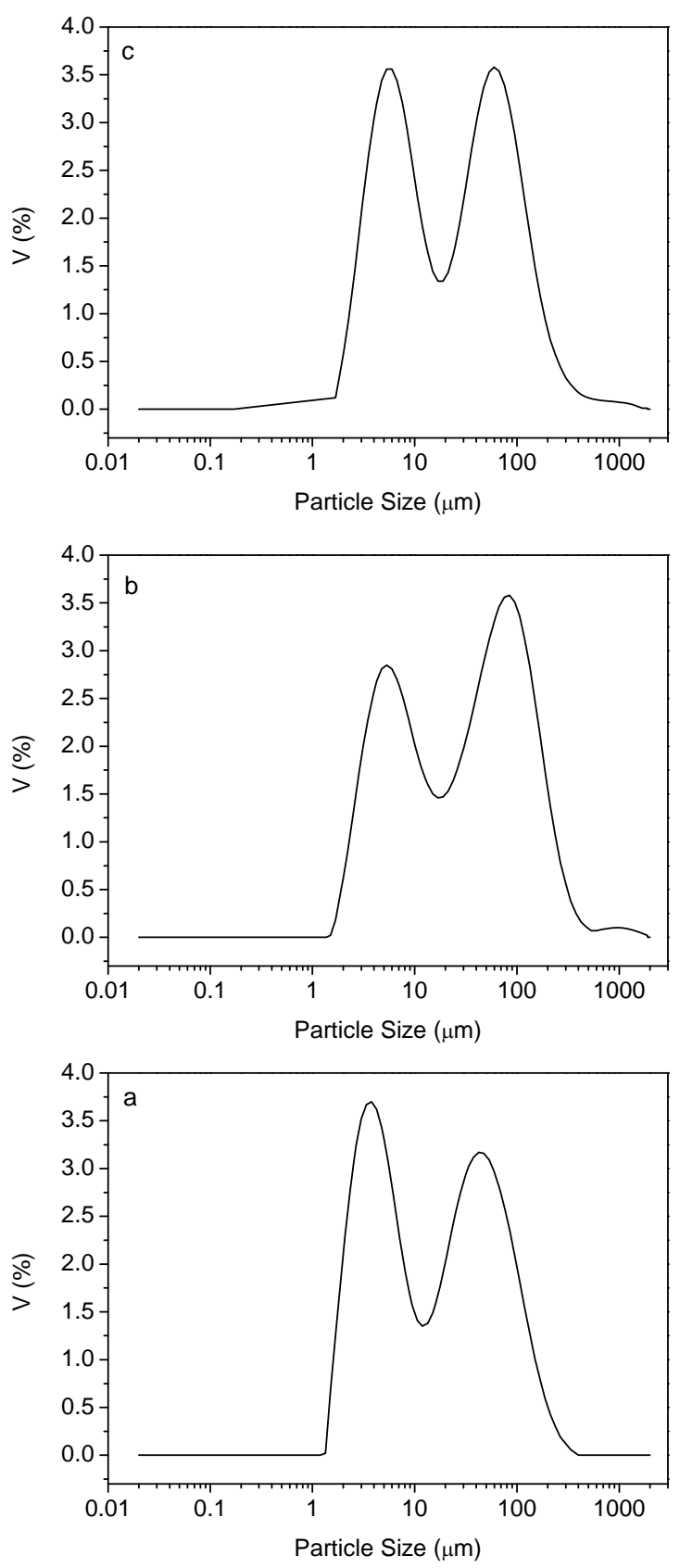